\title{
Upscaling of Long-Term U(VI) Desorption from Pore Scale Kinetics to Field-Scale Reactive Transport Models \\ (November 2006)
}

\author{
Carl I. Steefel ${ }^{1}$ \\ $\mathbf{L i ~} \mathbf{L i}^{1}$
}

in collaboration with

\author{
J. A. Davis ${ }^{2}$, G. P. Curtis ${ }^{2}$, B. D. Honeyman ${ }^{3}$, D. B. Kent ${ }^{2}$, M. Kohler ${ }^{2}$, D. R. Rodriguez ${ }^{3}$, K. \\ J. Johnson ${ }^{2}$, A. Miller ${ }^{3}$ \\ ${ }^{1}$ Lawrence Berkeley National Lab, Earth Sciences Division \\ ${ }^{2}$ U. S. Geological Survey \\ ${ }^{3}$ Colorado School of Mines, Golden, CO 80401
}

\section{Overview and Research Objectives}

The focus of the project is the development of scientifically defensible approaches for upscaling reactive transport models (RTM) through a detailed understanding of U(VI) desorption across several spatial scales: bench-, intermediate-, and field-scales. The central hypothesis of the project is that the development of this methodology will lead to a scientifically defensible approach for conceptual model development for multicomponent RTM at contaminated DOE sites, leading to predictive transport simulations with reduced uncertainty.

The project is designed to be a fully integrated study of upscaling centered on the fate and transport of hexavalent uranium (U(VI)) at the DOE UMTRA site near the town of Naturita, Colorado (Figure 1). Bench-scale experiments will be used to characterize the extent of desorbable $\mathrm{U}(\mathrm{VI})$ in the aquifer sediments and to develop detailed rate expressions describing the release of $\mathrm{U}(\mathrm{VI})$ at the pore-scale. Processes identified in the laboratory experiments that control $\mathrm{U}(\mathrm{VI})$ desorption and transport at the pore scale will be incorporated into a multicomponent reactive transport model. Experiments will be conducted at an intermediate-scale (several meters) through media constructed to have physical and chemical heterogeneities similar in scale and distribution to those observed in the field. These results will be used to determine how models can be upscaled, based on an understanding of the pore-scale processes. A geostatistical study will be carried out at the field site to characterize physical and chemical heterogeneities, and field-scale transport experiments will be conducted to examine further upscaling to the field. The findings from these multiscale investigations will provide a basis for a methodology to upscale the knowledge of processes at the pore scale to effective rates of the same processes occurring at the field scale. The research will provide guidance to DOE in selecting the type and quantity of data required to parameterize new conceptual models for contaminated field sites.

This report summarizes work performed at Lawrence Berkeley National Laboratory during the first six months of the project (March 15, 2006 through October 1, 2006) and is meant to supplement a report submitted by J.A. Davis in October 2006. The work scope at Berkeley Laboratory is focused on the pre- and post-experimental modeling of the intermediate-scale (2D and 3D) experiments. 


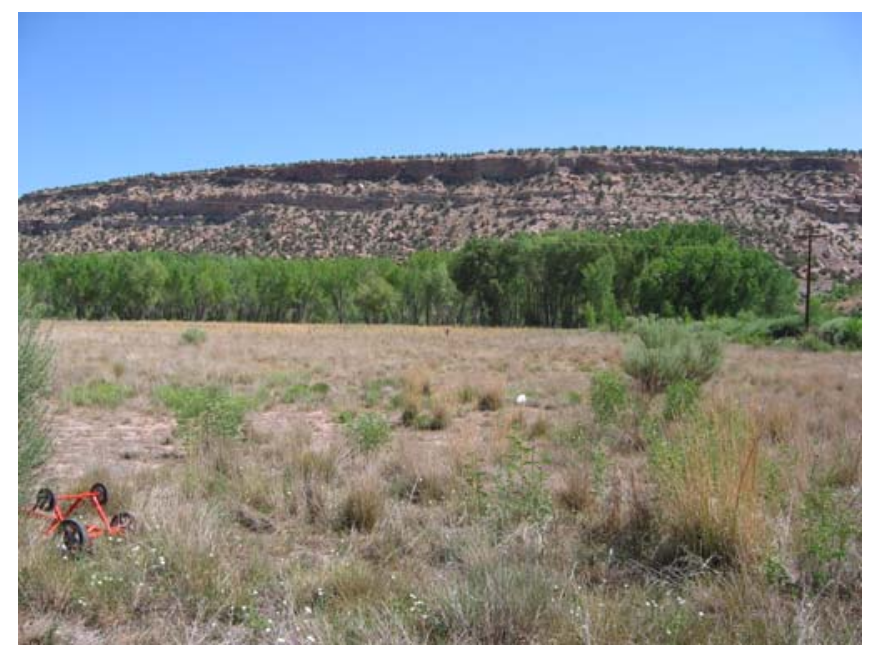

Figure 1: View of the Naturita site, western Colorado.

\section{Research Progress}

In this work, we investigate the possible effect of physical and chemical heterogeneities on uranium desorption kinetics from Naturita sediment using the reactive transport model CrunchFlow. We modeled two different intermediate-scale flow cell configurations of 1 meter in length and 0.5 meter in width, as shown in Figure 2. The homogeneous flow cell has the same effective physical and chemical properties as the heterogeneous flow cell, including porosity, permeability, total surface area, and adsorption site density. In addition, the total amount of absorbed and aqueous uranium initially present in the homogeneous and heterogeneous flow cells is the same. The heterogeneous flow cell is composed of three parallel layers in the direction of flow, with a fine-grained layer of 0.1 meter thickness embedded between two identical coarse-grained layers. The grain size distributions used are representative of contaminated sediments found at the Naturita site. The size of the fine grained layer is less than 63 microns in diameter, while that of the coarse-grained material is in the range of 3 to 5.6 millimeters. The fine-grained layer represents sediments with a higher fraction of clay minerals such as smectite and therefore has a slightly larger adsorption capacity. The adsorption site density of the fine-grained sediment is approximately 65 times larger than the coarse material, estimated based on the total amount of adsorbed uranium found at the site. The permeability contrast of the two layers is three orders of magnitude, calculated based on reasonable values for the grain size ranges considered. To capture the sorption processes, the two site model of Davis et al (2004) for the Naturita aquifer sediments.

Heterogeneous Flow Cell

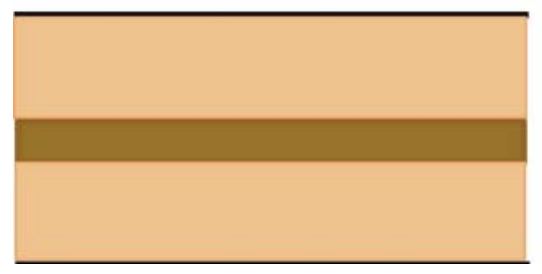

Homogeneous Flow Cell

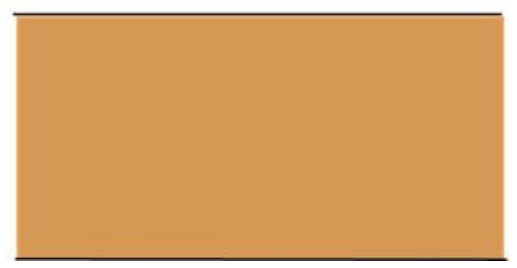

Figure 2: The setup of the heterogeneous and homogeneous intermediate-scale flow cells. 
To assess the effect of heterogeneity on uranium desorption, both flow cells were flushed with clean water of the same composition. Figure 3A shows snapshots of the aqueous uranium concentration profile in the heterogeneous column at different times. Although the uranium adsorbed on the coarse grains was quickly flushed out, it takes much longer for the uranium on the fine grained material to desorb. At $10^{8}$ seconds, there is still a trace amount of uranium left in the layer. As a result, the breakthrough curve shows an early decrease in uranium concentration and a long tail, as seen in Figure 3B. With an average flow velocity of $0.01 \mathrm{~m} / \mathrm{s}$, it takes more than $10^{8}$ seconds to desorb the uranium from the heterogeneous flow cell, compared to about $10^{6}$ seconds from the homogeneous flow cell. The results imply that under similar conditions, it may take a much longer time to flush the uranium from heterogeneous sediments than it would for homogenous sediments. As such, knowledge of the mineralogy of the contaminated sites and their spatial distribution can be very important for designing efficient remediation strategies.

A.

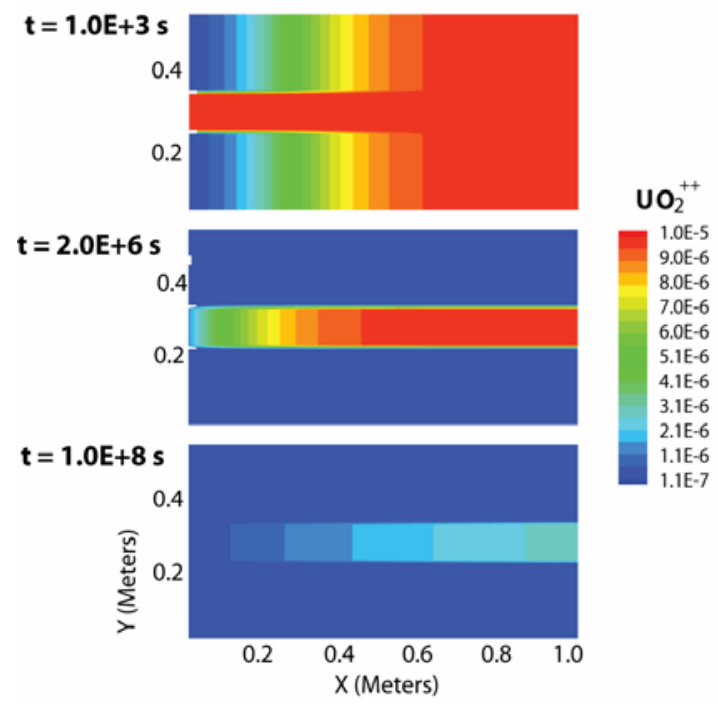

B.

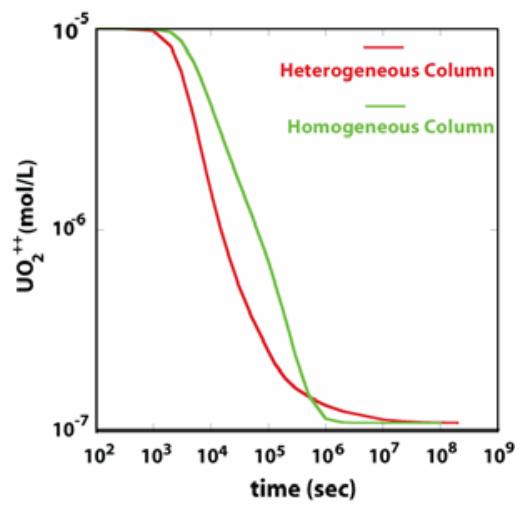

Figure 3. A. Snapshots of aqueous uranium concentrations in the heterogeneous flow cell. The absorbed uranium on the coarse-grained layers was flushed out first, while that on the finegrained layers desorbs much more slowly. B. Comparison of the breakthrough curves from the two flow cells.

\section{Planned Activities}

Future activities will include the implementation of sorption and desorption kinetics into CrunchFlow, which is currently handled as an equilibrium reaction. Once this new capability is added, experimentally-determined desorption kinetics will be included in new pre-modeling simulations of the heterogeneous flow cells.

\section{References}

Davis, J. A., D. E. Meece, M. Kohler and G. P. Curtis (2004) Approaches to surface complexation modeling of uranium(VI) adsorption on aquifer sediments, Geochim. Cosmochim. Acta, 68(18), 3621-3641. 